\title{
FATTY ACID COMPOSITION OF THE FRUITS OF SYZYGIUM ZEYLANICUM (L.) DC. VAR.
} ZEYLANICUM

\author{
DEVI R. C. BHANU, K. K. SABU* \\ Biotechnology and Bioinformatics Division, Jawaharlal Nehru Tropical Botanical Garden and Research Institute, Palode, \\ Thiruvananthapuram 695562, Kerala, India \\ Email: sabu@jntbgri.res.in
}

Received: 21 May 2017, Revised and Accepted: 22 Jul 2017

\begin{abstract}
Objective: Wild indigenous fruits are believed to be extremely nutritious, contributing a great deal to the general health of the tribal and rural population. To validate this claim, systematic studies are required to estimate their nutritional composition. The objective of the study was to analyze the fatty acid composition of Syzygium zeylanicum (L.) DC. var. zeylanicum.

Methods: The fatty acid composition of S. zeylanicum var. zeylanicum fruits were analysed by GC-MS/MS.

Results: The major fatty acids were cis-oleic acid (43.47 $\pm 0.62 \%)$ and linoleic acid $(31.14 \pm 0.35 \%)$. Total monounsaturated fatty acids in the sample was $44.21 \%$. Omega- 6 , omega-7 and omega- 9 fatty acids were detected. The polyunsaturated fatty acids in thefruits were linoleic acid $(31.14 \pm 0.35$ $\%)$ and arachidonic acid $(0.15 \pm 0.22 \%)$, whereas $24.51 \%$ of the total fatty acids were saturated. The ratio of unsaturated to saturated fatty acids was approximately 3:1. The order of abundance of fatty acids, in some of the healthiest oils, viz. olive, canola, peanut oils is, Oleic acid $>$ Linoleic acid $>$ Palmitic acid $>$ Stearic acid and the same order was observed in the present study.
\end{abstract}

Conclusion: Fruits of $S$. zeylanicum var. zeylanicum too shows a healthy balance between unsaturated and saturated fats.

Keywords: Fatty acids, GC-MS/MS, Wild fruits, PUFA, MUFA

(C) 2017 The Authors. Published by Innovare Academic Sciences Pvt Ltd. This is an open access article under the CC BY license (http://creativecommons.org/licenses/by/4.0/] DOI: http://dx.doi.org/10.22159/ijcpr.2017v9i5.22161

\section{INTRODUCTION}

The Western Ghats is a vast repository of plant and animal life. It has been recognized as one of the hottest hot-spots of biodiversity. Of particular interest, among the diverse flora of Western Ghats are the fruit-bearing indigenous trees. Nazarudeen (1999) reported 218 wild, edible fruit trees from forests of Kerala. In addition to fruits, the indigenous trees are a source of fire wood and timber [1]. These have wide adaptability and high degree of tolerance. The rural populace is familiar with many of these trees and their products, but the urban population is largely unaware of its benefits.

These are rarely cultivated or subjected to selection. The fruits are picked from the wild during the season. They are believed to be extremely nutritious; even more so than the favoured, cultivated varieties. This claim however requires validation. In fact to popularize these fruits in urban centres, scientific studies have to be undertaken to estimate their nutritional value.

For the current study, the zeylanicum variety of Syzygium zeylanicum was chosen. Syzygium zeylanicum (L.) DC. var. zeylanicum (family Myrtaceae) is a wild fruit yielding tree found in Indian states such as Maharashtra, Mysore, Kerala, Orissa and the Andamans [2]. It has opposite, stalked leaves that are purplish pink when young, green and glossy when mature. Flowers are white and faintly fragrant, found in clusters, at the ends of branches or axils of leaves. The fruits are small white berries, with a single greenish seed and thin pulp. The trunk is reddish brown and papery-flaky in mature specimens. The plant is hardy and tolerates poor soils and salt spray [3].

Almost all parts of the plant are useful. The plant is reported to be a stimulant and antirheumatic; a decoction of leaves and root is used as a vermifuge. The bark is a source of black dye. The wood is reddish or brown and used for rafts, construction and agricultural implements [2]. The leaves are used as a vegetable in Vietnam. The essential oil of leaves of $S$. zeylanicum is a very potent mosquito larvicide [4]. Methanolic extracts of $S$. zeylanicum leaves have shown high $\alpha$-glucosidase inhibitory activity and high polyphenol content [5]. The actual compound responsible for these activities was found to be Zeylaniin A, a new macrocyclic ellagitanin [6].

The aim of the present study was to profile the lipid fraction of the fruit; fat being an essential macronutrient of our diets.

\section{MATERIALS AND METHODS}

The fruits of Syzygium zeylanicum var. zeylanicum (SZZ) were collected during the fruiting season from, JNTBGRI, Palode, Thiruvananthapuram and University of Kerala, Karyavattam campus, Thiruvananthapuram. The fruits were washed to remove dirt and patted dry with paper towels. After removing seeds, the fruits were lyophilized.

The lyophilized samples were extracted with petroleum ether. The fatty acids in the lipid fraction were esterified to fatty acid methyl esters (FAMEs) using methanol. FAMEs were identified and quantified by gas chromatography (GC).

The fatty acid profile was generated through Gas ChromatographyMass Spectrometry/Mass Spectrometry Electron Ionisation Mode. The GC-MS/MS used was a Scion 436-GC Bruker model coupled with a Triple Quadruple mass spectrophotometer with fused silica capillary BR-5MS coloumn (30 mm x $0.25 \mathrm{~mm}$ i.d., $0.25 \mu \mathrm{m}$ film thickness). The carrier gas used was helium (99.999\%), at a constant flow rate of $1 \mathrm{ml} / \mathrm{min}$. The injection volume was $2 \mu \mathrm{l}$. The coloumn oven temperature program was as follows: $110^{\circ} \mathrm{C}$ hold for $3.5 \mathrm{~min}$, upto $200{ }^{\circ} \mathrm{C}$ at the rate of $10^{\circ} \mathrm{C} / \mathrm{min}$-No hold, upto $280{ }^{\circ} \mathrm{C}$ at the rate of $5{ }^{\circ} \mathrm{C} / \mathrm{min}-9$ min hold, Injector temperature $280^{\circ} \mathrm{C}$ and total $\mathrm{GC}$ running time was $37.5 \mathrm{~min}$. MS was operated in the positive electron ionization mode. The ionization energy was $70 \mathrm{eV}$. The solvent delay was 0-3.5 min. The inlet temperature was set at $290{ }^{\circ} \mathrm{C}$, source temperature at $250{ }^{\circ} \mathrm{C}$. MS Workstation 8 was used to handle mass spectra and chromatograms. 
Table 1: Mean fatty acid profiles of S. zeylanicum var. zeylanicum fruits

\begin{tabular}{lc}
\hline Fatty acids & \% total fatty acids \\
\hline Lauric Acid (C12:0) & $0.21 \pm 0.04$ \\
Myristic Acid (C14:0) & $0.60 \pm 0.11$ \\
Palmitoleic Acid (C16:1) & $0.18 \pm 0.06$ \\
Palmitic Acid (C16:0) & $18.82 \pm 0.21$ \\
Linoleic Acid (C18:2) & $31.14 \pm 0.35$ \\
cis-Oleic Acid (C18:1) & $43.47 \pm 0.62$ \\
Stearic Acid (C18:0) & $3.80 \pm 0.14$ \\
cis-11-Eicosenoic Acid (C20:1) & $0.56 \pm 0.23$ \\
Arachidic Acid (C20:0) & $1.08 \pm 0.16$ \\
Arachidonic Acid (C20:4) & $0.15 \pm 0.22$ \\
Total Saturated fatty acids & 24.51 \\
Total Monounsaturated fatty acids & 44.21 \\
Total Polyunsaturated fatty acid & 31.29 \\
\hline
\end{tabular}

Values are mean \pm standard error $(n=3)$

\section{RESULTS}

The fatty acid profile of $S Z Z$ fruits is shown in table 1 . The predominant fatty acid was cis-oleic acid ( $43.47 \pm 0.62 \%)$. The linoleic acid content of the sample was $31.14 \pm 0.35 \%$. The third most abundant fatty acid was Palmitic acid (18.82 $\pm 0.21 \%)$. Stearic acid and Arachidic acid showed, $3.80 \pm 0.14 \%$ and $1.08 \pm 0.16 \%$ respectively. Trace amounts of Lauric

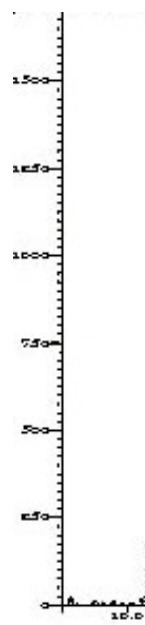

acid, Myristic acid, Palmitoleic acid, cis-11-Eicosenoic acid and Arachidonic acid were also detected. Total saturated fatty acids in the sample was $24.51 \%$. Monounsaturated fatty acids added up to $44.21 \%$. The polyunsaturated fatty acids (Linoleic acid and Arachidonic acid) showed an aggregate of $31.29 \%$. The ratio of saturated to unsaturated fatty acids was $75.5: 24.5$ which is roughly 3:1. Fig. 1 shows the GC-MS/MS chromatogram of $S Z Z$ fruit.

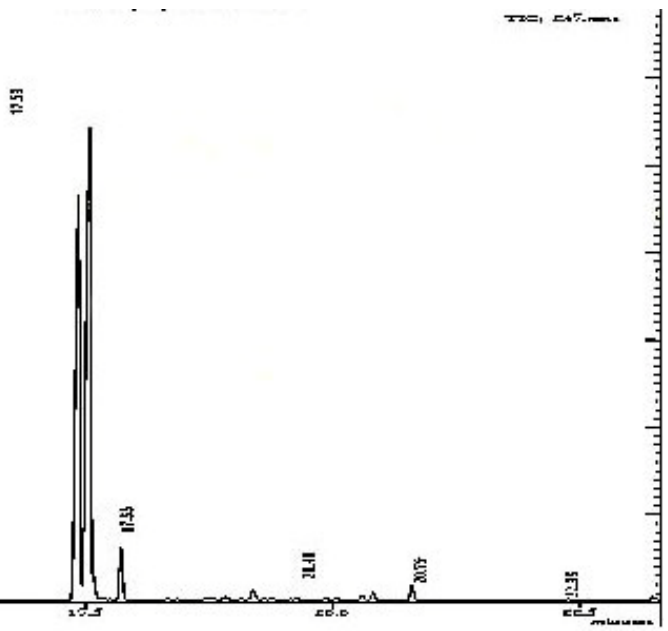

Fig. 1: GC-MS/MS chromatogram of S. zeylanicum var. zeylanicum fruit

\section{DISCUSSION}

Fatty acids that have only single bonds in their carbon chain are called monounsaturated fatty acids (MUFAs). The total MUFA content of $S$. zeylanicum var. zeylanicum fruit was $44.21 \%$. MUFAs are known to have numerous health benefits. Dietary intake of MUFA improves the blood lipid profile and helps lower blood glucose levels [7]. The incidence of breast cancer was observed to be considerably lower when the diet was rich in MUFA [8]. MUFA helps lower blood pressure and decreases the chance of developing coronary heart disease [9].

Olives and peanuts are good sources of MUFA, especially cis-oleic acid. The oleic acid content of olives and peanut are $75 \%$ and $48 \%$ respectively [10]. The most abundant fatty acid in SZZ fruit was cisoleic acid, whose relative composition was $43.47 \pm 0.62 \%$. Apart from being hypotensive, oleic acid also lowers the chance of developing ulcerative colitis [11]. It is known that obesity causes insulin resistance and type II diabetes. Vassilou et al. in 2009 reported that oleic acid reverses insulin resistance brought on by obesity and has a positive effect on type II diabetes [12]. The role of oleic acid in brain function was established by Hussain et al. in 2013 [13]. Lipid peroxidation is a degenerative process that eventually destroys the integrity of biological membranes and releases products that are harmful to the cell [14]. Oleic acid is less susceptible to lipid peroxidation than polyunsaturated fatty acids [15]. Polyunsaturated fatty acids (PUFAs) have more than one double bond in their carbon chain. The ratio of cis-oleic acid-PUFA in SZZ fruits was 43.47:31.29. A high ratio between oleic acid and polyunsaturated fatty acids protects lipids from peroxidation and oxidative damage [16].

The ratio of monounsaturated to polyunsaturated fatty acid in SZZ fruits was 44.21:31.29, which is approximately 7:5. According to studies, a high MUFA to PUFA ratio benefits the heart and keeps cardiovascular diseases at bay $[17,18]$.

The major PUFA in the analysed material was Linoleic acid. It is an omega- 6 fatty acid essential for the maintenance of healthy skin. Linoleic acid prevents loss of water from the skin and forms a barrier of sorts to undesirable chemicals in the environment [19]. The deficiency of linoleic acid manifests itself in the form of dry, scaly skin [20]. In a study conducted by Ando et al. in 1998, linoleic acid was found to have a skin lightening effect [21]

The fatty acid profile of $S Z Z$ fruits shows a 3:1 ratio of unsaturated to saturated fatty acids. The inclusion of saturated fatty acids (the fatty acids that lack double bonds in their structure) in the diet has negative implications on health. Substituting saturated fats in the diet with unsaturated fatty acids, improves lipid profile of the blood and decreases the risk of cardiovascular diseases [22]. The results of this study differs from a previous report by Shilpa and 
Krishnakumar (2015), in terms of the composition and proportion of fatty acids [23]. The current study has focused on the variety zeylanicum of $S$. zeylanicum, where as the earlier report does not mention the variety.

Table 2: Comparison of fatty acid composition of some common fruits [10] with S. zeylanicum var. zeylanicum

\begin{tabular}{|c|c|c|c|c|}
\hline \multirow[t]{2}{*}{ Plants } & \multicolumn{4}{|c|}{ Fatty acids } \\
\hline & C16:0 & C18:0 & C18:1 & C18:2 \\
\hline Syzygium zeylanicum var. zeylanicum & 18.82 & 3.8 & 43.47 & 31.14 \\
\hline Olive (Olea europea) & 11 & 2 & 76 & 8 \\
\hline Canola (Brassica napus) & 4 & 2 & 59 & 21 \\
\hline Peanut (Arachis hypogea) & 10 & 2 & 48 & 34 \\
\hline Sunflower (Helianthus annuus) & 7 & 3 & 21 & 69 \\
\hline Coconut (Cocos nucifera) & 9 & 3 & 6 & 2 \\
\hline Soyabean (Glycine max) & 11 & 4 & 24 & 54 \\
\hline Palm (Elaeis guineensis) & 46 & 4 & 38 & 10 \\
\hline
\end{tabular}

C16:0 Palmitic acid, C18:0 Stearic acid, C18:1 Oleic acid, C18:2 Linoleic acid

Table 2 compares the fatty acid composition of some commonly used oils with SZZ. The order of abundance of fatty acids, in some of the healthiest oils, viz. olive, canola, peanut oils is, Oleic acid $>$ Linoleic acid $>$ Palmitic acid $>$ Stearic acid. $S Z Z$ also follows this order. In SZZ palmitic acid content is quite high at $18.82 \pm 0.21 \%$, but it is compensated by much higher concentrations of unsaturated fatty acids. Like the other recommended oils, SZZ too shows a healthy balance between unsaturated and saturated fats.

\section{CONCLUSION}

The present study reveals that $S$. zeylanicum var. zeylanicumis a good source of beneficial fatty acids. It is suggested that the consumption of the fruits be encouraged and efforts be taken to popularize the fruits. Owing to high Linoleic acid content, the fruits may find use in the cosmetic industry.

\section{ACKNOWLEDGMENT}

The first author acknowledges the receipt of DST PURSE fellowship granted during this study. The authors thank the Director, JNTBGRI for providing the fruit samples to conduct the analysis.

\section{CONFLICTS OF INTERESTS}

All authors have none to declare

\section{REFERENCES}

1. Nazarudeen A. An assessment of the economically useful wild fruits of Kerala. Ph. D. Thesis. University of Kerala; 1999.

2. Anonymous. The Wealth of India. Vol X. CSIR. New Delhi; 2008. p. 107.

3. Boo CM, Omar-Hor K, Ou-Yang CL. 1001 Garden Plants in Sinagapore. $2^{\text {nd }}$ ed. National Parks Board; 2003.

4. Govindarajan M, Benelli G. $\alpha$-Humulene and $\beta$-elemene from Syzygium zeylanicum (Myrtaceae) essential oil: highly effective and eco-friendly larvicides against Anopheles subpictus, aedesalbopictus, and culextritaeniorhynchus (Diptera: Culicidae). Parasitol Res 2016;115:2771-8.

5. Mai TT, Thu NN, Tien PG, Chuyen NV. Alpha-glucosidase inhibitory and antioxidant activities of vietnamese edible plants and their relationships with polyphenol contents. J Nutr Sci Vitamind 2007;53:267-76.

6. Nomi Y, Shimizu S, Sone Y, Tuyet MT, Gia TP, Kamiyama M, Shibamoto $\mathrm{T}$, et al. Isolation and antioxidant activity of zeylaniin a, a new macrocyclic ellagitannin from Syzygium zeylanicum leaves. J Agric Food Chem 2012;60:10263-9.

7. Donaghue KC, Pena MM, Chan AKF, Blades BL, King J, Storlien LH, et al. Beneficial effects of increasing monounsaturated fat intake in adolescents with type 1 diabetes. Diabetes Res Clin Pract 2000;48:193-9.

8. Wolk A, Bergström R, Hunter D, Willett W, Ljung H, Holmberg L, Bergkvist L, et al. A prospective study of association of monounsaturated fat and other types of fat with risk of breast cancer. Arch Intern Med 1998;158:41-5.

9. Schwingshackl L, Hoffmann G. Monounsaturated fatty acids and risk of cardiovascular disease: synopsis of the evidence available from systematic reviews and meta-analyses. Nutrients 2012;4:1989-2007.

10. Hildebrand D. Production of unusual fatty acids in plants. AOCS Lipid library; 1980.

11. De Silva PS, Luben R, Shrestha SS, Khaw KT, Hart AR. Dietary arachidonic and oleic acid intake in ulcerative colitis etiology: a prospective cohort study using 7-day food diaries. Eur J Gastroenterol Hepatol 2014;26:11-8.

12. Vassiliou EK, Gonzalez A, Garcia C, Tadros JH, Chakraborty G, Toney JH. Oleic acid and peanut oil high in oleic acid reverse the inhibitory effect of insulin production of the inflammatory cytokine TNF- $\alpha$ both in vitro and in vivo systems. Lipids Health Disease 2009;8:25.

13. Hussain G, Schmitt F, Loeffler JP, de Aguilar JLG. Fatting the brain: a brief of recent research. Frontiers Cellular Neurosci 2013;7:144.

14. Mylonas C, Kouretas D. Lipid peroxidation and tissue damage. In Vivo 1999;13:295-309.

15. Lee C, Barnett J, Reaven PD. Liposomes enriched in oleic acid are less susceptible to oxidation and have lessproinflammatory activity when exposed to oxidizing conditions. J Lipid Res 1998;39:1239-47.

16. Haug A, Hostmark AT, Harstad OM. Bovine milk in human nutrition-a review. Lipids Health Disease 2007;6:25.

17. de Lorgeril M, Renaud S, Mamelle N, Salen P, Martin JL, Monjaud I, et al. Mediterranean alpha-linolenic acid-rich diet in secondary prevention of coronary heart disease. Lancet 1994;11:1454-9.

18. Nicolos RJ, Woolfrey B, Wilson TA, Scollin P, Handelman G, Fisher R. Decreased aortic early atherosclerosis and associated risk factors in hypercholesterolemic hamsters fed a high-midoleic acid compared to a high-linoleic acid oil. J Nutr Biochem 2004;15:540-7.

19. Elias PM, Brown BE, Ziboh VA. The permeability barrier in essential fatty acid deficiency: evidence for a direct role for linoleic acid in barrier function. J Invest Dermatol 1980;74:230-3.

20. Ziboh VA, Miller CC, Cho Y. Metabolism of polyunsaturated fatty acids by skin epidermal enzymes: generation of antiinflammatory and antiproliferative metabolites. Am J Clin Nutr 2000;71:361s-366s.

21. And H, Ryu A, Hashimoto A, Oka M, Ichihashi M. Linoleic acid and $\alpha$-linolenic acid lightens ultraviolet-induced hyperpigmentation of the skin. Arch Dermatol Res 1998;290:375-81.

22. Siri-Tarino PW, Sun Q, Hu FB, Krauss RM. Saturated fatty acids and risk of coronary heart disease: modulation by replacement nutrients. Curr Atherosclerosis Reports 2010;12:384-90.

23. Shilpa KJ, Krishnakumar G. Nutritional, fermentation and pharmacological studies of Syzygium caryophyllatum (L.) Alston and Syzygium zeylanicum (L.) DC fruits. Cogent Food Agric 2015;1:1018-694.

\section{How to cite this article}

- $\quad$ Devi RC Bhanu, KK Sabu. Fatty acid composition of the fruits of Syzygium zeylanicum (L.) DC. Var. Zeylanicum. Int J Curr Pharm Res 2017;9(5):155-157. 